\title{
Eficácia e Seletividade de Herbicidas do Grupo das imidazolinonas Aplicados em Pós-Emergência de Plantas Daninhas Monocotiledôneas na Cultura do Girassol CL ${ }^{1}$
}

\author{
Efficacy and Selectivity of Herbicides from the Imidazolinone Group Applied in Post-Emergence \\ of Monocotyledon weeds on CL Sunflower Culture
}

\author{
FRANCISCHINI, A.C. ${ }^{2}$, SANTOS, GIZELLY, G. ${ }^{2}$, CONSTANTIN, J. ${ }^{3}$, GHIGLIONE, H. ${ }^{4}$, \\ VELHO, G.F. ${ }^{5}$, GUERRA, N. ${ }^{2}$ e BRAZ, G.B.P. ${ }^{6}$
}

\begin{abstract}
RESUMO - O controle das plantas daninhas, em geral, é realizado pelo uso de herbicidas, porém essa prática é limitada na cultura do girassol, por haver apenas dois produtos registrados para essa cultura (alachlor e trifluralin). Entretanto, o uso de novas tecnologias pode facilitar o controle das plantas daninhas com herbicidas que possuem amplo espectro de controle. Assim, o objetivo deste trabalho foi avaliar a eficácia e seletividade de herbicidas do grupo das imidazolinonas aplicados em pós-emergência de plantas daninhas monocotiledôneas na cultura do girassol Clearfield (CL). Para isso, foram instalados dois experimentos em campo. Os tratamentos e as respectivas doses em $\mathrm{g} \mathrm{ha}^{-1}$ foram: trifluralin (1.800) aplicado em préemergência, fluazifop-p-butil (187) e imazapic+imazapyr nas doses de [36,75+12,25], [52,5+17,5], $[12,25+36,75]$ e $[17,5+52,5]$, aplicados em pós-emergência, além de duas testemunhas sem aplicação de herbicida, sendo uma sem capina e outra com capina. Foram realizadas avaliações de controle para Eleusine indica, Brachiaria plantaginea, Lolium multiflorum, Digitaria insularis, Cenchrus echinatus e Digitaria horizontalis, fitointoxicação do girassol Clearfield, estande e produtividade em $\mathrm{kg} \mathrm{ha}^{-1}$. De acordo com os resultados, verificou-se que o uso do sistema CL mostrou-se uma ótima opção para áreas com infestação de plantas daninhas monocotiledôneas, pois possibilita a aplicação de herbicidas inibidores da enzima acetolactato sintase (ALS), obtendo excelente controle das plantas daninhas, além de não provocar injúrias visuais, mantendo o estande inicial, sem alterar a produtividade da cultura.
\end{abstract}

Palavras-chave: imazapic, imazapyr, controle.

\begin{abstract}
Weed control is generally accomplished by the use of herbicides. However, this practice is limited in sunflower cultivation, since only two products are registered for the culture (alachlor and trifluralin).The use of new technologies can facilitate weed control with herbicides with broad spectrum control. Therefore, the objective of this study was to evaluate the efficacy and selectivity of herbicides of the imidazolinone group applied in post-emergence on monocotyledon weeds in Clearfield sunflower cultivation. Thus, two experiments were installed in the field. The treatments and their doses in $g \mathrm{ha}^{-1}$ were: trifluralin (1800) applied at pre-emergence, fluazifop-pbutyl (187) and imazapic+imazapyr doses [36.75+12.25], [52.5+17.5], [12.25+36.75] and [17.5+52.5] applied at post-emergence, plus two controls without herbicide, one without weeding and the other with weeds. Control was evaluated for Eleusine indica, Brachiaria plantaginea, Lolium multiflorum, Digitaria insularis, Digitaria horizontalis and Cenchrus echinatus, Clearfield Sunflower phytotoxicity, stand and yield in $\mathrm{kg} \mathrm{ha}^{-1}$. The results obtained showed that
\end{abstract}

Recebido para publicação em 7.10.2011 e aprovado em 5.4.2012.

2 Eng-âa-Agr ${ }^{\mathrm{a}}$, M.Sc., Doutorando do Programa de Pós-Graduação em Agronomia, Universidade Estadual de Maringá -NAPD/UEM, Bolsista CAPES, <aleconstantin@agronoma.eng.br><gizelly@agronoma.eng.br ><naiara.guerra@hotmail.com>; ${ }^{3}$ Eng Professor Associado, Coordenador do Núcleo de Estudos Avançados em Ciência das Plantas Daninhas, NAPD/UEM, Dep. de Agronomia, Universidade Estadual de Maringá, UEM. Bolsista CNPq, <constantin@teracom. com.br $>$; ${ }^{4}$ Eng ${ }^{\circ}-A g r{ }^{\circ}$, BASF - R\&D Projects Manager Latin America - Herbicides \& Biotechnology; ${ }^{5}$ Engo-Ago‥, BASF - Integrated Projects Management - R\&D Latin America; ${ }^{6}$ Engo-Agro ${ }^{\circ}$, M.Sc., Doutorando do Programa de Pós-Graduação em Agronomia, Universidade Estadual de Maringá, NAPD/UEM, Bolsista CNPq, <guilhermebrag@gmail. com>.

Planta Daninha, Viçosa-MG, v. 30, n. 4, p. 843-851, 2012 
the use of the Clearfield system proved to be a great option for areas with monocotyledon weed infestation, since it allows the application of acetolactate synthase (ALS) - inhibiting herbicides achieving excellent weed control, without causing visual injury, and maintaining the original stand, without affecting crop yield.

Keywords: imazapic, imazapyr, control.

\section{INTRODUÇÃO}

O girassol pertence ao gênero Helianthus, que compreende cerca de 50 espécies nativas nas Américas (Schiling \& Heiser, 1981). Essa diversidade de espécies permite que essas plantas possuam habitats altamente variáveis (Schneiter, 1997), sendo cultivadas em países como Argentina, China, Índia, Rússia, Ucrânia, Estados Unidos, Brasil, entre outros.

O cultivo do girassol tem crescido em todo o mundo em decorrência do aumento da sua utilização. Espécies como Helianthus tuberosus têm sido usadas como forragem e na alimentação, enquanto Helianthus annus é cultivado para extração de óleo vegetal e pode ser usado ainda como planta ornamental, junto com Helianthus argophyllus e Helianthus debillis (Seiler \& Reiseberg, 1997).

Devido à grande demanda na alimentação humana e como óleo vegetal, a cultura do girassol na safra de 2010/2011 atingiu a quarta posição entre as oleaginosas mais produzidas no mundo; seu consumo mundial nessa safra foi de cerca de 10,964 mil toneladas, ficando atrás apenas de culturas como palma, soja e canola (CONAB, 2010).

Com produção de 102,4 mil toneladas na safra de 2010/2011 (CONAB, 2010), a cultura do girassol tende a ter aumento na área de plantio no Brasil, devido ao incentivo dado pelo Governo Federal, visando à produção de biodiesel (Castro et al., 2005; Silva et al., 2007).

Dessa maneira, com o aumento da área cultivada, há maior preocupação com o controle das plantas daninhas, pois o potencial produtivo do girassol pode ser prejudicado pela competição por água, luz, nutrientes, $\mathrm{CO}_{2} \mathrm{e}$ espaço, causando prejuízos que podem variar de 23 a $70 \%$ de perda de rendimento dos aquênios (Vidal \& Merotto Jr., 2001).
No entanto, o uso de herbicidas visando à redução da interferência das plantas daninhas na cultura do girassol é limitado, em decorrência do número reduzido de herbicidas registrados para essa cultura: alachlor e trifluralin (Castro et al., 2005; Brasil, 2010).

Devido à escassez de herbicidas registrados para a cultura do girassol e à dificuldade extrema em descobrir novas moléculas ou novos modos de ação, faz-se necessário expandir a utilidade de produtos com amplo espectro de controle e com bom perfil ambiental, sendo a resistência geneticamente melhorada uma estratégia útil para promover o uso de herbicidas seletivos a esse tipo de cultura (Tan et al., 2005).

Assim, plantas geneticamente melhoradas estão sendo inseridas na agricultura - é o caso de plantas resistentes a herbicidas do grupo das imidazolinonas. Os mais utilizados incluem imazapyr, imazapic, imazethapyr, imazamox, imazameth-abenz e imazaquin, os quais controlam as plantas daninhas pela inibição da enzima aceto-hidroxiácido sintase (AHAS), também chamada de acetolactato sintase (ALS) (Croughan, 2003), que é uma enzima essencial para a biossintese de cadeia ramificada de aminoácidos nas plantas.

Esses herbicidas controlam amplo espectro de plantas daninhas de folha larga e estreita, são eficazes em baixas taxas de aplicação, têm baixa toxicidade em mamíferos e possuem um perfil ambiental favorável (Tan et al., 2005).

Por conseguinte, o objetivo deste trabalho foi avaliar a eficácia e seletividade de herbicidas do grupo das imidazolinonas aplicados em pós-emergência de plantas daninhas monocotiledôneas na cultura do girassol CL.

\section{MATERIAL E MÉTODOS}

Dois experimentos foram realizados no campo, em áreas distintas, no período de 
novembro de 2010 a fevereiro de 2011 . O experimento 1 encontrava-se na Fazenda Experimental de Iguatemi, Maringá-PR, e o experimento 2, em Iguatemi, distrito de Maringá-PR, cujas coordenadas são $23^{\circ} 20^{\prime} 58.77^{\prime \prime}$ de latitude sul e 52.04'28.94" de longitude oeste, a 526 metros de altitude, e 23⒉'43.97" de latitude sul e $52^{\circ} 04^{\prime} 15.17 "$ de longitude oeste, a 548 metros de altitude, respectivamente.

As amostras de solo foram submetidas a análises para determinar as características químicas e granulométricas. Os resultados das análises apresentaram as características a seguir.

O solo da área experimental 1 apresentava $\mathrm{pH}$ em água de 5,90; 2,45 $\mathrm{cmol}_{\mathrm{c}} \mathrm{de}^{+}+\mathrm{Al}^{+3} \mathrm{dm}^{-3}$ de solo; $1,91 \mathrm{cmol}_{\mathrm{c}} \mathrm{dm}^{-3} \mathrm{de} \mathrm{Ca}^{+2} ; 0,72 \mathrm{cmol}_{\mathrm{c}} \mathrm{dm}^{-3}$ de $\mathrm{Mg}^{+2}$; 0,17 $\mathrm{cmol}_{\mathrm{c}} \mathrm{dm}^{-3} \mathrm{de} \mathrm{K}^{+} ; 9,07 \mathrm{mg} \mathrm{dm}^{-3} \mathrm{de}$ P; $5,28 \mathrm{~g} \mathrm{dm}^{-3}$ de C; $32 \%$ de areia grossa; $48 \%$ de areia fina; $2 \%$ de silte; e $18 \%$ de argila.

O solo da área experimental 2 apresentava $\mathrm{pH}$ em água de 5,$40 ; 3,18 \mathrm{cmol}_{\mathrm{c}}$ de $\mathrm{H}^{+}+\mathrm{Al}^{+3} \mathrm{dm}^{-3}$ de solo; $2,58 \mathrm{cmol}_{\mathrm{c}} \mathrm{dm}^{-3} \mathrm{de} \mathrm{Ca}^{+2} ; 0,85 \mathrm{cmol}_{\mathrm{c}} \mathrm{dm}^{-3}$ de $\mathrm{Mg}^{+2} ; 0,20 \mathrm{cmol}_{\mathrm{c}} \mathrm{dm}^{-3} \mathrm{de} \mathrm{K}^{+} ; 2,58 \mathrm{mg} \mathrm{dm}^{-3} \mathrm{de}$ $\mathrm{P} ; 2,58 \mathrm{~g} \mathrm{dm}^{-3} \mathrm{de} \mathrm{C}$; $15 \%$ de areia grossa; $29 \%$ de areia fina; $6 \%$ de silte; e $50 \%$ de argila.

A semeadura do girassol dos dois experimentos foi realizada no dia $15 / 11 / 2010$. O cultivar utilizado foi CF $503 \mathrm{CL}$, com densidade de semeadura de cinco sementes por metro linear e espaçamento entre linhas de $0,90 \mathrm{~m}$, totalizando 55.550 plantas ha-1. A adubação de plantio foi realizada com o formulado NPK 8-20-20 na dose de $350 \mathrm{~kg} \mathrm{ha}^{-1}$, aplicado na linha de plantio. O início da emergência das plantas de girassol ocorreu no dia 20/11/2010 em ambos os ensaios. Vinte dias após a emergência, foi feita a aplicação de $60 \mathrm{~kg} \mathrm{ha}^{-1}$ de nitrogênio em cobertura, utilizando-se ureia como fonte de $\mathrm{N}$.

Os atuais herbicidas registrados para cultura do girassol são produtos aplicados em pré-emergência da cultura, como o trifluralin. Assim, optou-se por duas alternativas: um tratamento em pré-emergência (trifluralin) e um em pós-emergência (fluazifop-p-butil), produto com potencial para ser utilizado na cultura do girassol, segundo trabalhos realizados por Brighenti \& Castro (2008), mesmo sem registro para a cultura no Brasil. Portanto, a aplicação do herbicida em pré-emergência foi realizada no dia 15/11/2010, logo após o plantio da cultura, e 15 dias após a semeadura (DAS) $(30 / 11 / 2010)$ foram feitas as aplicações em pós-emergência da cultura e das plantas daninhas.

No experimento 1, nas aplicações em pósemergência, a cultura do girassol apresentavase em estádio de quatro a seis folhas e com altura de 12 a $16 \mathrm{~cm}$, e as plantas daninhas avaliadas (Eleusine indica, Brachiaria plantaginea e Lolium multiflorum) apresentavam-se com um a dois perfilhos e densidades de 28,12 e 18 plantas $\mathrm{m}^{-2}$.

No experimento 2, nas aplicações em pós-emergência, o girassol apresentava-se em estádio de quatro a seis folhas e com altura de 14 a $17 \mathrm{~cm}$, e as plantas daninhas avaliadas (Digitaria insularis, Cenchrus echinatus e Digitaria horizontalis) apresentavam-se com um a dois perfilhos e densidades de 17, 24 e 34 plantas $\mathrm{m}^{-2}$.

Os tratamentos e as doses em $\mathrm{g} \mathrm{ha}^{-1}$ utilizados neste trabalho foram: testemunha sem capina e sem aplicação de herbicida, misturas formuladas de imazapic+imazapyr $[36,75+$ $12,25]$, imazapic+imazapyr $[52,50+17,50]$, imazapic+imazapyr $[12,25+36,75]$, imazapic+ imazapyr $\left[17,50+52,50 \mathrm{~g} \mathrm{ha}^{-1}\right]$, e os produtos isolados fluazifop-p-butil (187) e trifluralin (1800) e testemunha capinada sem aplicação de herbicida.

Para as aplicações, utilizou-se pulverizador costal à base de $\mathrm{CO}_{2}$, equipado com seis pontas tipo leque XR 110.02 espaçadas de $0,50 \mathrm{~m}$, pressurizado de forma a proporcionar volume de aplicação de $200 \mathrm{~L} \mathrm{ha}^{-1}$, sob pressão

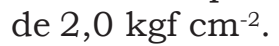

O delineamento experimental utilizado foi de blocos ao acaso com oito tratamentos e quatro repetições, sendo um dos tratamentos a testemunha capinada, que recebeu capinas manuais sempre que necessário, mantendo assim as parcelas sem a presença de plantas daninhas. As parcelas foram compostas por 3,5 $\mathrm{m}$ de largura e $6 \mathrm{~m}$ de comprimento, totalizando $21 \mathrm{~m}^{2}$.

As características avaliadas foram: porcentagem de controle (escala visual de 0-100\%, em que 0 significa ausência de sintomas e 100 a morte total das plantas daninhas), 
fitointoxicação da cultura, por meio da escala EWRC (EWRC, 1964), que vai de 1 a 9, em que 1 significa ausência de sintomas e 9 a morte das plantas. As avaliações foram realizadas aos $15,30,45$ e 60 dias após a semeadura (DAS); aos 15 DAS foram feitas as avaliações do padrão trifluralin aplicado em pré-emergência.

O estande inicial foi determinado aos 15 e 22 DAS, por meio da contagem da população de plantas em um metro linear da linha de semeadura.

Também foi feita a avaliação da produtividade $\left(\mathrm{kg} \mathrm{ha}^{-1}\right)$ para a área experimental 1. Para evitar o ataque de pássaros, foi realizada a cobertura de 15 capítulos por parcela com sacolas de tecido de TNT, logo após a polinização. A colheita das 15 plantas foi realizada manualmente no período de maturação fisiológica (90 dias após a emergência), quando as plantas apresentavam coloração escura no caule e no capítulo.

Para análise dos dados obtidos, realizouse análise de variância, e as médias dos tratamentos foram comparadas pelo teste de Tukey a 5\% de probabilidade, utilizando-se o programa estatístico Sisvar.

\section{RESULTADOS E DISCUSSÃO}

\section{Controle visual das plantas daninhas - experimento 1}

Nas Tabelas 1, 2 e 3 encontram-se os controles das plantas daninhas Eleusine indica, Brachiaria plantaginea e Lolium multiflorum, respectivamente.

Nas avaliações realizadas aos 15 DAS, o trifluralin aplicado em pré-emergência proporcionou excelente controle das plantas daninhas avaliadas. Esses resultados corroboram os trabalhos realizados por Alonso et al. (2007), os quais observaram que o uso de trifluralin nas doses entre 135 e $2.250 \mathrm{~g} \mathrm{ha}^{-1}$, aplicado em pré-emergência na cultura da mandioca, proporcionou controle acima de $98,75 \%$ para E. indica, B. plantaginea, B. decumbens e D. horizontalis.

Em relação às avaliações realizadas em pós-emergência, o fluazifop-p-butil não proporcionou controle satisfatório aos 30 DAS apenas para L. multiflorum. Contudo, até o término do experimento (60 DAS) foram observados excelentes controles, atingindo $100 \%$ para E. indica, B. plantaginea e L. multiflorum. Esses resultados concordam com os dados obtidos por Silva et al. (2005), os quais verificaram que mesmo em doses baixas de fluazifop-p-butil (25 e $62 \mathrm{~g} \mathrm{ha}^{-1}$ ) houve controle satisfatório de $B$. plantaginea aos 14 dias após a emergência da planta daninha.

No tocante ao controle obtido pelas misturas formuladas de imazapic+imazapyr, o controle proporcionado para $B$. plantaginea na primeira avaliação em pós-emergência (30 DAS) mostrou-se excelente em todas as doses testadas, variando de 88 a $98,75 \%$ de controle. Em contrapartida, o controle de E. indica e L. multiflorum não foi satisfatório para todas as doses de imazapic+imazapyr, sendo inferior ao da testemunha capinada e dos tratamentos alternativos trifluralin, aplicado em pré-emergência, e fluazifop-p-butil, aplicado em pós-emergência.

O controle insatisfatório dessas plantas daninhas aos 30 DAS provavelmente se deve ao mecanismo de ação desses herbicidas. Imazapic e imazapyr são produtos inibidores da enzima acetolactato sintase (ALS), e a ação deles é resultado da redução dos niveis de três aminoácidos alifáticos de cadeia ramificada (valina, leucina e isoleucina), através da inibição da aceto-hidroxiácido sintase (AHAS), uma enzima comum na via biossintética desses aminoácidos. Essa inibição interrompe a síntese de proteína, que por sua vez interfere na sintese de DNA e no crescimento celular (Rodrigues \& Almeida, 2005).

Embora a interrupção do crescimento e a morte das regiões meristemáticas ocorram logo após a aplicação, a clorose das folhas novas e a necrose dos tecidos podem demorar em algumas espécies até duas semanas. Esse efeito pode ser observado para E. indica e L. multiflorum; aos 45 e 60 DAS, todas as doses testadas de imazapic+imazapyr proporcionaram controle satisfatório acima de $80 \%$ para L. multiflorum, enquanto para $E$. indica apenas a menor dose da mistura formulada de imazapic+imazapyr $[36,75+12,25] \mathrm{g}^{-1} \mathrm{a}^{-1}$ não proporcionou controle eficiente aos 45 e aos 60 DAS. 
Tabela 1 - Porcentagem de controle de Eleusine indica após a aplicação dos herbicidas em pré e em pós-emergência da cultura do girassol Clearfield. Experimento 1, Maringá-PR, 2010/2011

\begin{tabular}{|c|c|c|c|c|}
\hline \multirow{2}{*}{ Tratamento } & \multicolumn{4}{|c|}{ Controle de Eleusine indica (\%) } \\
\hline & $15 \mathrm{DAS}$ & $30 \mathrm{DAS}$ & 45 DAS & $60 \mathrm{DAS}$ \\
\hline 1. Testemunha & 0,00 & $0,00 \mathrm{e}$ & $0,00 \mathrm{f}$ & $0,00 \mathrm{e}$ \\
\hline 2. [Imazapic+Imazapyr] $]^{1 /}$ & 0,00 & $64,00 \mathrm{~d}$ & $71,00 \mathrm{e}$ & $74,50 \mathrm{~d}$ \\
\hline 3. [Imazapic+Imazapyr] $]^{1 /}$ & 0,00 & $74,25 \mathrm{c}$ & $80,00 \mathrm{~d}$ & $83,50 \mathrm{c}$ \\
\hline 4. [Imazapic+Imazapyr] $]^{1 /}$ & 0,00 & $76,50 \mathrm{c}$ & $87,00 \mathrm{c}$ & $91,00 \mathrm{~B}$ \\
\hline 5. [Imazapic+Imazapyr] $]^{1 /}$ & 0,00 & $78,75 \mathrm{c}$ & $88,00 \mathrm{c}$ & $91,50 \mathrm{~B}$ \\
\hline 6. Fluazifop-p-butil ${ }^{1 /}$ & 0,00 & $93,50 \mathrm{~b}$ & $100,00 \mathrm{a}$ & $100,00 \mathrm{~A}$ \\
\hline 7. Trifluralin ${ }^{2 / /}$ & 100,00 & $96,25 \mathrm{ab}$ & $95,75 \mathrm{~b}$ & $95,00 \mathrm{~B}$ \\
\hline 8. Testemunha capinada & 100,00 & $100,00 \mathrm{a}$ & $100,00 \mathrm{a}$ & $100,00 \mathrm{~A}$ \\
\hline CV $(\%)$ & - & 3,49 & 2,24 & 2,50 \\
\hline DMS & - & 6,03 & 4,13 & 4,71 \\
\hline
\end{tabular}

Médias seguidas da mesma letra na coluna não diferem entre si a 5\% de probabilidade pelo teste de Tukey. DAS: dias após a semeadura. ${ }^{1 /}$ PÓS

= aplicação em pós-emergência da cultura e da planta daninha. ${ }^{2 /}$ PRÉ = aplicação em pré-emergência da cultura e da planta daninha.

Tabela 2 - Porcentagem de controle de Brachiaria plantaginea após a aplicação dos herbicidas em pré e em pós-emergência da cultura do girassol Clearfield. Experimento 1, Maringá-PR, 2010/2011

\begin{tabular}{|c|c|c|c|c|}
\hline \multirow{2}{*}{ Tratamento } & \multicolumn{4}{|c|}{ Controle de Brachiaria plantaginea $(\%)$} \\
\hline & $15 \mathrm{DAS}$ & 30 DAS & 45 DAS & $60 \mathrm{DAS}$ \\
\hline 1. Testemunha & 0,00 & $0,00 \mathrm{e}$ & $0,00 \mathrm{c}$ & $0,00 \mathrm{c}$ \\
\hline 2. [Imazapic+Imazapyr] $]^{1 /}$ & 0,00 & $88,00 \mathrm{~d}$ & $99,50 \mathrm{ab}$ & $100,00 \mathrm{a}$ \\
\hline 3. [Imazapic+Imazapyr] $]^{1 /}$ & 0,00 & $90,50 \mathrm{~cd}$ & $99,25 \mathrm{ab}$ & $100,00 \mathrm{a}$ \\
\hline 4. [Imazapic+Imazapyr] $]^{1 /}$ & 0,00 & $92,75 \mathrm{bc}$ & $99,50 \mathrm{ab}$ & $100,00 \mathrm{a}$ \\
\hline 5. [Imazapic+Imazapyr] $]^{1 /}$ & 0,00 & $95,00 \mathrm{~b}$ & $98,75 \mathrm{ab}$ & $100,00 \mathrm{a}$ \\
\hline 6. Fluazifop-p-butil ${ }^{1 /}$ & 0,00 & $98,75 \mathrm{a}$ & $100,00 \mathrm{a}$ & $100,00 \mathrm{a}$ \\
\hline 7. Trifluralin ${ }^{2 / 2}$ & 100,00 & $99,50 \mathrm{a}$ & $98,50 \mathrm{~b}$ & $97,00 \mathrm{~b}$ \\
\hline 8. Testemunha capinada & 100,00 & $100,00 \mathrm{a}$ & $100,00 \mathrm{a}$ & $100,00 \mathrm{a}$ \\
\hline CV $(\%)$ & - & 1,70 & 0,66 & 0,57 \\
\hline DMS & - & 3,35 & 1,35 & 1,18 \\
\hline
\end{tabular}

Médias seguidas da mesma letra na coluna não diferem entre si a $5 \%$ de probabilidade pelo teste de Tukey. DAS: dias após a semeadura. $\stackrel{1 /}{ }$ PÓS = aplicação em pós-emergência da cultura e da planta daninha. ${ }^{2 /}$ PRÉ = aplicação em pré-emergência da cultura e da planta daninha.

Tabela 3 - Porcentagem de controle de Lolium multiflorum após a aplicação dos herbicidas em pré e em pós-emergência da cultura do girassol Clearfield. Experimento 1, Maringá-PR, 2010/2011

\begin{tabular}{|c|c|c|c|c|}
\hline \multirow{2}{*}{ Tratamento } & \multicolumn{4}{|c|}{ Controle de Lolium multiflorum (\%) } \\
\hline & $15 \mathrm{DAS}$ & 30 DAS & 45 DAS & $60 \mathrm{DAS}$ \\
\hline 1. Testemunha & 0,00 & $0,00 \mathrm{~d}$ & $0,00 \mathrm{e}$ & $0,00 \mathrm{~d}$ \\
\hline 2. [Imazapic+Imazapyr] $]^{1 /}$ & 0,00 & $60,75 \mathrm{c}$ & $81,00 \mathrm{~d}$ & $86,75 \mathrm{c}$ \\
\hline 3. [Imazapic+Imazapyr] $]^{1 /}$ & 0,00 & $74,50 \mathrm{~b}$ & $89,25 \mathrm{c}$ & $98,00 \mathrm{ab}$ \\
\hline 4. [Imazapic+Imazapyr] $]^{1 /}$ & 0,00 & $72,75 \mathrm{~b}$ & $88,00 \mathrm{c}$ & $96,00 \mathrm{ab}$ \\
\hline 5. [Imazapic+Imazapyr] $]^{1 /}$ & 0,00 & $74,00 \mathrm{~b}$ & $89,75 \mathrm{c}$ & $98,00 \mathrm{ab}$ \\
\hline 6. Fluazifop-p-butil ${ }^{1 /}$ & 0,00 & $64,50 \mathrm{c}$ & $93,50 \mathrm{~b}$ & $100,00 \mathrm{a}$ \\
\hline 7. Trifluralin ${ }^{2 / /}$ & 100,00 & $98,25 \mathrm{a}$ & $98,00 \mathrm{a}$ & $97,50 \mathrm{ab}$ \\
\hline 8. Testemunha capinada & 100,00 & $100,00 \mathrm{a}$ & $100,00 \mathrm{a}$ & $100,00 \mathrm{a}$ \\
\hline CV $(\%)$ & - & 2,55 & 1,91 & 1,38 \\
\hline DMS & - & 4,11 & 3,61 & 2,75 \\
\hline
\end{tabular}

Médias seguidas da mesma letra na coluna não diferem entre si a $5 \%$ de probabilidade pelo teste de Tukey. DAS: dias após a semeadura. ${ }^{1 /}$ PÓS = aplicação em pós-emergência da cultura e da planta daninha. ${ }^{2}$ PRÉ = aplicação em pré-emergência da cultura e da planta daninha. 


\section{Controle visual das plantas daninhas - experimento 2}

Nas Tabelas 4, 5 e 6 encontram-se os controles das plantas daninhas Digitaria insularis, Cenchrus echinatus e Digitaria horizontalis, respectivamente.

O trifluralin aplicado em pré-emergência proporcionou $100 \%$ de controle das três ervas avaliadas aos 15 DAS, sendo os resultados semelhantes aos apresentados para $E$. indica, B. plantaginea e L. multiflorum avaliadas na área experimental 1. O excelente controle das plantas daninhas proporcionado pelo trifluralin nos dois experimentos se deve principalmente ao mecanismo de ação do herbicida, o qual inibe a divisão e elongação celular, com pouca ou nenhuma atividade foliar (Roman et al, 2007; Christofoletti, 2008); a maioria das gramíneas anuais e dicotiledôneas de sementes pequenas não emerge (Rodrigues \& Almeida, 2005).

Para as avaliações em pós-emergência, verificou-se que fluazifop-p-butil mostrou-se excelente opção para controle de C. echinatus e $D$. insularis, obtendo controle mínimo de $97,75 \%$ da primeira à última avaliação. Para $D$. horizontalis, o controle efetivo foi verificado a partir dos 45 DAS.

A mesma tendência observada para os controles proporcionados pela mistura formulada imazapic+imazapyr na área experimental 1 foi verificada na segunda área. Assim, em se tratando dos herbicidas imazapic+ imazapyr, como mencionado no controle visual das plantas daninhas (experimento 1), as doses testadas desta mistura formulada também proporcionaram excelente controle de $D$. insularis a partir dos 30 DAS e de $D$. horizontalis e C. echinatus a partir dos 45 DAS.

O excelente controle com o uso de herbicidas do grupo químico das imidazolinonas também foi observado por Marchesan et al. (2011), que constataram controle de $90 \%$ do arroz-vermelho nos sistemas que utilizaram o arroz Clearfield, contra $69 \%$ de controle no sistema convencional. O controle efetivo do arroz-vermelho em áreas de produção de arroz Clearfield também foi observado por Sha et al. (2007), com a aplicação do herbicida imazethapyr na região sul dos EUA.

\section{Fitointoxicação da cultura}

Em relação à fitointoxicação causada pelos herbicidas aplicados em pré e pós-emergência, não foram observadas injúrias na cultura no girassol CL tanto nos controles alternativos realizados com fluazifop-p-butil e trifluralin como quando se utilizaram as misturas formuladas de imazapic+imazapyr; assim, de acordo com a escala EWRC (EWRC, 1964), todos os tratamentos obtiveram 1,0 , justificando a ausência dessa tabela.

Esses dados corroboram os resultados obtidos por Brighenti \& Castro (2008), os quais verificaram que em aplicações com o herbicida fluazifop-p-butil combinado ou não com fertilizante foliar (boro) não houve nenhum sintoma de fitotoxicidade na cultura do girassol. Os herbicidas inibidores da acetil-CoA carboxilase (ACCase), como o fluazifop-p-butil, são empregados como graminicidas pós-emergentes em diversas culturas dicotiledôneas, como soja, algodão, feijão, batata, fumo, entre outras (Vidal et al., 2000).

A seletividade das culturas resistentes aos herbicidas do grupo das imidazolinonas também foi observada por Almeida et al. (2004), que, trabalhando com o híbrido DKB $901 \mathrm{CL}$, não constataram sintomas de fitointoxicação após a aplicação da mistura formulada de imazapic+imazapyr.

Como pode ser observado nas duas áreas experimentais, a mistura formulada de imazapic+imazapyr obteve controle efetivo das plantas daninhas avaliadas e não provocou injúrias à cultura do girassol CL.

\section{Estande e produtividade}

As aplicações de trifluralin e fluazifop-pbutil e também das misturas formuladas de imazapic+imazapyr, além de proporcionarem excelente controle de algumas plantas daninhas, como foi mostrado no presente trabalho, não alteraram significativamente o estande final da cultura, mesmo com as aplicações em pós-emergência, mantendo uma média de 4,5 plantas por metro linear, ou seja, não houve diferença significativa entre os tratamentos para a variável estande $(\mathrm{p}<0,05)$. 
Tabela 4 - Porcentagem de controle de Digitaria insularis após a aplicação dos herbicidas em pré e em pós-emergência da cultura do girassol Clearfield. Experimento 2, Maringá-PR, 2010/2011

\begin{tabular}{|c|c|c|c|c|}
\hline \multirow{2}{*}{ Tratamento } & \multicolumn{4}{|c|}{ Controle de Digitaria insularis (\%) } \\
\hline & $15 \mathrm{DAS}$ & $30 \mathrm{DAS}$ & $45 \mathrm{DAS}$ & $60 \mathrm{DAS}$ \\
\hline 1. Testemunha & 0,00 & $0,00 \mathrm{~d}$ & $0,00 \mathrm{c}$ & $0,00 \mathrm{c}$ \\
\hline 2. [Imazapic+Imazapyr] $]^{1 /}$ & 0,00 & $95,00 \mathrm{c}$ & $98,50 \mathrm{ab}$ & $100,00 \mathrm{a}$ \\
\hline 3. [Imazapic+Imazapyr] $]^{1 /}$ & 0,00 & $97,00 \mathrm{bc}$ & $99,25 \mathrm{ab}$ & $100,00 \mathrm{a}$ \\
\hline 4. [Imazapic+Imazapyr] $]^{1 /}$ & 0,00 & $96,00 \mathrm{bc}$ & $97,75 \mathrm{~b}$ & $100,00 \mathrm{a}$ \\
\hline 5. [Imazapic+Imazapyr $]^{1 /}$ & 0,00 & $96,50 \mathrm{bc}$ & $99,50 \mathrm{a}$ & $100,00 \mathrm{a}$ \\
\hline 6. Fluazifop-p-butil ${ }^{1 /}$ & 0,00 & $97,75 \mathrm{~b}$ & $100,00 \mathrm{a}$ & $100,00 \mathrm{a}$ \\
\hline 7. Trifluralin ${ }^{2 /}$ & 100,00 & $100,00 \mathrm{a}$ & $99,25 \mathrm{ab}$ & $98,75 \mathrm{~b}$ \\
\hline 8. Testemunha capinada & 100,00 & $100,00 \mathrm{a}$ & $100,00 \mathrm{a}$ & $100,00 \mathrm{a}$ \\
\hline CV $(\%)$ & - & 1,05 & 0,85 & 0,39 \\
\hline DMS & - & 2,12 & 1,74 & 0,80 \\
\hline
\end{tabular}

Médias seguidas da mesma letra na coluna não diferem entre si a 5\% de probabilidade pelo teste de Tukey. DAS: dias após a semeadura. ${ }^{1 /}$ PÓS

= aplicação em pós-emergência da cultura e da planta daninha. ${ }^{2 /}$ PRÉ = aplicação em pré-emergência da cultura e da planta daninha.

Tabela 5 - Porcentagem de controle de Cenchrus echinatus após a aplicação dos herbicidas em pré e em pós-emergência da cultura do girassol Clearfield. Experimento 2, Maringá-PR, 2010/2011

\begin{tabular}{|c|c|c|c|c|}
\hline \multirow{2}{*}{ Tratamento } & \multicolumn{4}{|c|}{ Controle de Cenchrus echinatus (\%) } \\
\hline & $15 \mathrm{DAS}$ & 30 DAS & 45 DAS & $60 \mathrm{DAS}$ \\
\hline 1. Testemunha & 0,00 & $0,00 \mathrm{c}$ & $0,00 \mathrm{c}$ & $0,00 \mathrm{c}$ \\
\hline 2. [Imazapic+Imazapyr] $]^{1 /}$ & 0,00 & $78,25 \mathrm{~b}$ & $98,50 \mathrm{ab}$ & $100,00 \mathrm{a}$ \\
\hline 3. $[\text { Imazapic+Imazapyr }]^{1 /}$ & 0,00 & $78,25 \mathrm{~b}$ & $99,00 \mathrm{ab}$ & $100,00 \mathrm{a}$ \\
\hline 4. [Imazapic+Imazapyr] $]^{1 /}$ & 0,00 & $75,75 \mathrm{~b}$ & $98,25 \mathrm{~b}$ & $100,00 \mathrm{a}$ \\
\hline 5. [Imazapic+Imazapyr] $]^{1 /}$ & 0,00 & $76,75 \mathrm{~b}$ & $98,00 \mathrm{~b}$ & $100,00 \mathrm{a}$ \\
\hline 6. Fluazifop-p-butil ${ }^{1 /}$ & 0,00 & $100,00 \mathrm{a}$ & $100,00 \mathrm{a}$ & $100,00 \mathrm{a}$ \\
\hline 7. Trifluralin ${ }^{2 /}$ & 100,00 & $98,50 \mathrm{a}$ & $97,50 \mathrm{~b}$ & $96,00 \mathrm{~b}$ \\
\hline 8. Testemunha capinada & 100,00 & $100,00 \mathrm{a}$ & $100,00 \mathrm{a}$ & $100,00 \mathrm{a}$ \\
\hline CV $(\%)$ & - & 3,96 & 0,85 & 0,47 \\
\hline DMS & - & 7,13 & 1,74 & 0,96 \\
\hline
\end{tabular}

Médias seguidas da mesma letra na coluna não diferem entre si a 5\% de probabilidade pelo teste de Tukey. DAS: dias após a semeadura. ${ }^{1 /}$ PÓS

$=$ aplicação em pós-emergência da cultura e da planta daninha. $\stackrel{2}{2}$ PRÉ = aplicação em pré-emergência da cultura e da planta daninha.

Tabela 6 - Porcentagem de controle de Digitaria horizontalis após a aplicação dos herbicidas em pré e em pós-emergência da cultura do girassol Clearfield. Experimento 2, Maringá-PR, 2010/2011

\begin{tabular}{|c|c|c|c|c|}
\hline \multirow{2}{*}{ Tratamento } & \multicolumn{4}{|c|}{ Controle de Digitaria horizontalis $(\%)$} \\
\hline & $15 \mathrm{DAS}$ & 30 DAS & 45 DAS & 60 DAS \\
\hline 1. Testemunha & 0,00 & $0,00 \mathrm{~d}$ & $0,00 \mathrm{~d}$ & $0,00 \mathrm{c}$ \\
\hline 2. [Imazapic+Imazapyr $]^{1 /}$ & 0,00 & $74,00 \mathrm{~b}$ & $94,75 \mathrm{ab}$ & $100,00 \mathrm{a}$ \\
\hline 3. $[\text { Imazapic+Imazapyr }]^{1 /}$ & 0,00 & $73,75 \mathrm{~b}$ & $93,00 \mathrm{~b}$ & $100,00 \mathrm{a}$ \\
\hline 4. [Imazapic+Imazapyr] $]^{1 /}$ & 0,00 & $74,50 \mathrm{~b}$ & $95,25 \mathrm{ab}$ & $100,00 \mathrm{a}$ \\
\hline 5. [Imazapic+Imazapyr] $]^{1 /}$ & 0,00 & $75,75 \mathrm{~b}$ & $97,00 \mathrm{ab}$ & $100,00 \mathrm{a}$ \\
\hline 6. Fluazifop-p-butil ${ }^{1 /}$ & 0,00 & $60,00 \mathrm{c}$ & $85,00 \mathrm{c}$ & $100,00 \mathrm{a}$ \\
\hline 7. Trifluralin ${ }^{2 / 1}$ & 100,00 & $95,50 \mathrm{a}$ & $99,00 \mathrm{a}$ & $97,75 \mathrm{~b}$ \\
\hline 8. Testemunha capinada & 100,00 & $100,00 \mathrm{a}$ & $100,00 \mathrm{a}$ & $100,00 \mathrm{a}$ \\
\hline CV $(\%)$ & - & 3,11 & 2,85 & 0,39 \\
\hline DMS & - & 5,13 & 5,61 & 0,80 \\
\hline
\end{tabular}

Médias seguidas da mesma letra na coluna não diferem entre si a $5 \%$ de probabilidade pelo teste de Tukey. DAS: dias após a semeadura. ${ }^{1 /}$ PÓS = aplicação em pós-emergência da cultura e da planta daninha. ${ }^{2}$ PRÉ = aplicação em pré-emergência da cultura e da planta daninha. 
Esses resultados assemelham-se aos dos trabalhos de Santos et al. (2007), que, avaliando o estande de arroz CL (Clearfield), não observaram diferenças significativas no estande de plantas com a aplicação de herbicidas ALS, como a mistura formulada de imazethapyr+imazapic.

Quanto ao fator produtividade de grãos (Tabela 7), observou-se que a testemunha capinada obteve produção de $2.112,25 \mathrm{~kg} \mathrm{ha}^{-1}$, apresentando rendimento superior ao da testemunha sem capina e do tratamento com formulado imazapic+imazapyr [36,75+ $\left.12,25 \mathrm{~g} \mathrm{ha}^{-1}\right]$, na ordem de 28 e $22 \%$ respectivamente. Isso mostra a queda da produtividade da cultura do girassol em decorrência da competição causada pela interferência das plantas daninhas na cultura, confirmada por Vidal \& Merotto Jr. (2001), os quais afirmam que prejuízos causados por espécies infestantes na cultura do girassol podem variar de 23 a $70 \%$ de perda de rendimento de aquênios, em razão da presença de espécies daninhas.

Esses resultados assemelham-se aos obtidos por Brighenti et al. (2004), que, estudando a convivência do girassol com as plantas daninhas, concluíram que a convivência destas com a cultura pode ocasionar perdas diárias de $1,1 \mathrm{~kg} \mathrm{ha}^{-1}$ no rendimento de óleo e de $2,5 \mathrm{~kg}$ ha ${ }^{1}$ na produtividade de grãos. Já na ausência total de plantas daninhas, até $30 \mathrm{DAE}$ (dias após emergência ), o ganho diário foi de 6,5 e $14,4 \mathrm{~kg} \mathrm{ha}^{-1}$ para o rendimento de óleo e para produtividade de grãos, respectivamente.

Verifica-se que a menor produtividade foi obtida na testemunha sem capina e no tratamento de $[36,75+12,25] \mathrm{g}^{-1}$ de imazapic+ imazapyr, enquanto os demais tratamentos contendo a mistura formulada de imazapic+ imazapyr, além de terem apresentado taxas de controle ótimas das plantas daninhas monocotiledôneas, proporcionaram produtividades semelhantes às dos tratamentos alternativos, conseguindo assim inibir a interferência das plantas daninhas, mantendo a produtividade do girassol CL.

Como mencionado, não houve queda na produtividade quando se utilizaram herbicidas do grupo químico das imidazolinonas em girassol CL. O mesmo foi observado por Marchesan et al. (2011), que, comparando o sistema de
Tabela 7 - Produtividade em $\left(\mathrm{kg} \mathrm{ha}^{-1}\right)$ obtida na área experimental 1, após a aplicação dos tratamentos em pré e em pós-emergência do girassol Clearfield (CF 503 CL), no controle de plantas daninhas monocotiledôneas. Maringá-PR, 2010/2011

\begin{tabular}{|c|c|c|}
\hline Tratamento & $\begin{array}{c}\text { Dose } \\
\left(\mathrm{g} \mathrm{ha}^{-1}\right)\end{array}$ & $\begin{array}{c}\text { Produção } \\
\left(\mathrm{kg} \mathrm{ha}^{-1}\right)\end{array}$ \\
\hline 1. Testemunha & - & $1.506,75 \mathrm{c}$ \\
\hline 2. ${\text { [Imazapic+Imazapyr] }{ }^{1 /}}^{1 /}$ & {$[36,75+12,25]$} & $1.726,25 \mathrm{cb}$ \\
\hline 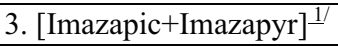 & {$[52,5+17,5]$} & $1.816,50 \mathrm{ab}$ \\
\hline 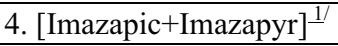 & {$[12,25+36,75]$} & $1.873,75 \mathrm{ab}$ \\
\hline 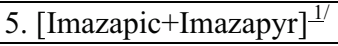 & {$[17,5+52,5]$} & $1.905,75 \mathrm{ab}$ \\
\hline 6. Fluazifop-p-butil ${ }^{1 /}$ & 187 & $1.952,25 \mathrm{Ab}$ \\
\hline 7. Trifluralin $\stackrel{2 /}{-}$ & 1.800 & $2.005,75 \mathrm{Ab}$ \\
\hline 8. Testemunha capinada & - & $2.112,25 \mathrm{a}$ \\
\hline CV $(\%)$ & \multicolumn{2}{|c|}{10,04} \\
\hline DMS & \multicolumn{2}{|c|}{306,91} \\
\hline
\end{tabular}

Médias seguidas da mesma letra na coluna não diferem entre si a $5 \%$ de probabilidade pelo teste de Tukey. DAS: dias após a semeadura. 1/ PÓS = aplicação em pós-emergência da cultura e da planta daninha.

2/ PRÉ = aplicação em pré-emergência da cultura e da planta daninha.

produção Clearfield com o sistema convencional de produção de arroz, alcançaram os melhores resultados com o primeiro. Além disso, produtos originários do grupo das imidazolinonas possuem propriedades químicas que favorecem a permanência desses herbicidas no solo, aumentando assim o controle de novos fluxos de plantas daninhas, devido à atividade residual.

Esses fatores podem colaborar quando inseridas culturas seletivas com tecnologia Clearfield no sistema de rotação de cultura, como foi testado por Süzer \& Büyük (2010). Esses autores inferiram que as populações selvagens de mostarda e grama, comumente encontradas no cultivo de cereais, podem ser suprimidas quando cultivado o girassol CL antecedendo a cultura de cereais, provavelmente devido à redução do banco de sementes das plantas invasoras.

Em suma, os resultados apresentados evidenciaram que o sistema Clearfield na cultura do girassol proporcionou maior flexibilidade no controle de plantas daninhas monocotiledôneas, por se tratar de um cultivo que permite a aplicação de herbicidas inibidores da enzima ALS, como a mistura formulada de imazapic+imazapyr. Ele proporcionou controles excelentes para as plantas infestantes 
Brachiaria plantaginea, Digitaria insularis, Cenchrus echinatus, Lolium multiflorum, Eleusine indica e Digitaria horizontalis, não interferindo na produtividade e no estande da cultura do girassol CL.

\section{LITERATURA CITADA}

ALMEIDA, J. C. V. et al. Eficácia de imazapic+imazapyr no controle de tiririca (Cyperus rotundus) em milho (Zea mays) tolerante às imidazolinonas. Planta Daninha, v. 22, n. 1, p. 151-156, 2004.

ALONSO, D. G et al. Avaliação da eficácia e viabilidade de Trifluralina Nortox Gold na cultura da mandioca. R. Raízes Amidos Trop., v. 3, n. 1, p. 36, 2007.

BRIGHENTI, A. M. et al. Períodos de interferência de plantas daninhas na cultura do girassol. Planta Daninha, v. 22, n. 2, p. 251-257, 2004.

BRIGHENTI, A. M.; CASTRO, C. Boron foliar application on sunflower (Helianthus annuus L.) associated with herbicides. Sci. J. Helia, v. 31, n. 48, p. 127-136, 2008.

CASTRO, C.; LEITE, R. M. V. B.; BRIGHENTI, A. M. Girassol no Brasil. Londrina: Embrapa Soja, 2005. 641 p.

CHRISTOFOLETTI, P. J. Aspectos de resistência de plantas daninhas a herbicidas. 3.ed. Londrina: Associação Brasileira de Ação à Resistência de Plantas aos Herbicidas, 2008.

COMPANHIA NACIONAL DE ABASTECIMENTO CONAB, 2010. Girassol. Disponível em: <http:// www.conab.gov.br/OlalaCMS/uploads/arquivos/ 10_11_16_13_07_58_apresentacaogirassol..pdf > . Acesso: 10 ago. 2011.

CROUGHAN, T. P. Clearfield rice: It's not a GMO. Louisiana Agric., v. 46, n. 4, p. 24-26, 2003.

EUROPEAN WEED RESEARCH COUNCIL - EWRC. Report of the 3th and 4th meetings of EWRC - Comittee of methods in weed research. Weed Res., v. 4, n. 1, p. 88, 1964.

MARCHESAN, E. Produtividade, fitotoxicidade e controle de arroz-vermelho na sucessão de cultivo de arroz irrigado no Sistema Clearfield ${ }^{\circledR}$. Ci. Rural, v. 41, n. 1, p. 17-24, 2011.

BRASIL. Ministério da Agricultura, Pecuária e Abastecimento. Agrofit, 2010. Site: $<$ http://agrofit.agricultura. gov.br/ agrofit_cons/principal_agrofit_cons $>$ Acesso em: 1ํㅡov. 2010.
SCHILLING, E. E.; HEISER, C. B. Infrageneric classification os Helianthus (Compositae). Taxon, v. 30, n. 1, p. 393-403, 1981.

SCHNEITER, A. A. Sunflower technology and production. 35.ed. Madison: American Society of Agronomy, 1997. p. 834.

SEILER, G.J.; RIESEBERG,.L.H. Systematics, origins, and germplasm resources of the wild and domesticated sunflower. In: SCHNEITER, A. A., (Ed.). Sunflower technology and production. Madison: 1997. cap. 3, p.67-111.

SHA, X. Y.; LINSCOMBE, S. D.; GROTH, D. E. Field evaluation of imidazolinone-tolerant Clearfield rice (Oryza sativa L.). Crop. Sci., v. 47, n. 9, p. 1177-1185, 2007.

SÜZER, S.; BÜYÜK, H. Residual effects of spraying imidazolinone family herbicides on clearfield sunflower production from the point of view of crop rotation. Sci. J. Helia, v. 33, n. 52, p. 25-36, 2010.

RODRIGUES, B. N.; ALMEIDA, F. S. Guia de herbicidas. 5.ed. Londrina: 2005. 591 p.

ROMAN, E. S. et al. Como funcionam os herbicidas - da biologia à aplicação. Passo Fundo: Berthier, 2007. 160 p.

SANTOS, F. M. et al. Controle químico de arroz-vermelho na cultura do arroz irrigado. Planta Daninha, v. 25, n. 2, p. 405-412, 2007.

SILVA, A. C. et al. Interação competitiva de B. brizantha e $B$. plantaginea sob doses reduzidas de fluazifop-p-butil, aplicadas em diferentes épocas. Planta Daninha, v. 23, n. 1, p. 79-84, 2005.

SILVA, M. L. O. et al. Crescimento e produtividade do girassol cultivado na entressafra com diferentes lâminas de água. R. Bras. Eng. Agríc. Amb., v. 11, n. 5, p. 1807-1929, 2007.

TAN, S. et al. Imidazolinone-tolerant crops: history, current status and future. Pest Manag. Science, v. 61, n. 3, p. 246257, 2005.

VIDAL, R. A. et al. Seletividade do herbicida fluazifop-pbutil para cucurbitáceas. Planta Daninha, v. 18, n. 3, p. 413-17, 2000.

VIDAL, R. A.; MEROTTO Jr., A. Herbicidologia. Porto Alegre: Edição do Autor, 2001. 152 p. 